
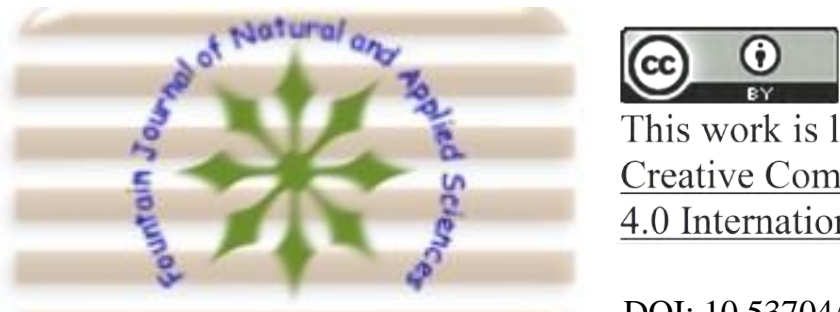

This work is licensed under Creative Commons Attribution

4.0 International License.

DOI: 10.53704/fujnas.v10i1.340

A publication of College of Natural and Applied Sciences, Fountain University, Osogbo, Nigeria.

Journal homepage: www.fountainjournals.com

ISSN: 2354-337X(Online),2350-1863(Print)

\title{
Birth Preparedness Practice: Profiling Determining Factors for Male Involvement in Southern Nigeria
}

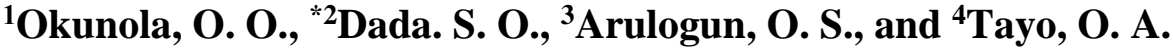 \\ ${ }^{1}$ Department of Clinical Nursing, University College Hospital, Ibadan, Nigeria \\ ${ }^{2}$ Department of Research, Innovation and International Cooperation, Babcock University, Nigeria \\ ${ }^{3}$ Department of Health Promotion and Education, University of Ibadan, Nigeria \\ ${ }^{4}$ Babcock University Teaching Hospital, Ilishan, Nigeria
}

\begin{abstract}
Maternal mortality remains high in most African countries including Nigeria. Delays in seeking care for normal delivery and obstetric emergencies are the major determinants of maternal mortality. Birth Preparedness (BP) has been found to be very effective in reducing these delays. Females have always been focused on birth preparedness studies. This study was however designed to investigate male involvement in the practice of birth preparedness in Southern, Nigeria. This was a descriptive study design using a validated structured interviewer-administered questionnaire. A multistage sampling technique was used to select 302 married men in the community. Knowledge on BP was measured on a 48-point knowledge scale and a 30-point practice scale was used to determine male involvement in BP. Data were analysed using descriptive and inferential statistics at $p<0.05$. The mean age of the respondents was $38.0 \pm 8.6$ years. Majority (59.9\%) of the respondents had good knowledge on birth preparedness. Mean score for level of involvement was $21.52 \pm 5.4$ and $43.0 \%$ of the respondents had good score. Identified factors militating against male involvement in birth preparedness include low socioeconomic status, busy work schedule, cultural belief, and poor attitude of health workers. There was significant association between knowledge of birth preparedness and religion as well as level of male involvement in BP $(\mathrm{p}=0.018 ; 0.001$ respectively). This study showed low level of male involvement in birth preparedness. Several factors were identified to be responsible for this. There is therefore the need for sustainable community health education programmes to motivate and encourage male involvement in birth preparedness.
\end{abstract}

Keywords: Birth preparedness, Knowledge, Male involvement, Practices

\section{Introduction}

Maternal and infant mortality remains a global public health challenge. World Health Organization (WHO, 2019), estimated that every day, approximately 810 women die from preventable causes related to pregnancy and childbirth, $94 \%$ of these occur in developing countries and higher among women living in rural areas and among poorer communities. SubSaharan Africa and Southern Asia account for about $86 \%$ of the global burden of maternal death. The maternal mortality ratio in low income

*Corresponding author: +234 -7064202918.

Email address: dadasam@babcock.edu.ng 
countries is 462 per 1000 live births as compared with 11 per 1000 live births in high income countries (WHO, 2019). Birth preparedness, a process of planning for normal birth and anticipating the actions needed in case of emergency which includes identification of skilled birth attendants, identification of appropriate health facility closest to the pregnant woman's location, preparing for funds for birth related expenses, planning for transportation to the health facility at the onset of labour and identification of compatible blood donors in case of emergency has been documented to reduce delay for seeking maternal healthcare (JHPIEGO, 2004). Birth preparedness does generally address 'three delays' which includes; delay in recognition of problem, delay in seeking care, and delay in receiving care at health facility. These delays represent barriers that often result in preventable maternal deaths (JHPIEGO, 2004, Udofia et al, 2004). The World Health Organization (2015) however, recommended that male involvement is one of the interventions needed to improve maternal and newborn health.

Around the world, men play critical roles in women's ability to seek health care, yet, more often than not, they are uninformed about women's reproductive health needs or their own. A study by Wai et al (2015) has documented that most cultures, especially in Africa, regard pregnancy and delivery as a female domain; therefore, men are often not expected to accompany their wives to the antenatal care (ANC) clinic or be present during delivery. As decision maker for the family, decisions around when, where and even if, a woman should have access to healthcare often fall on men. Particularly in patriarchal societies like the South Western Nigeria, the health status of women and children suffer especially where women have little control over family finances, choice of food, little say in decision making and restricted freedom of movement (Dada et al, 2020). This study therefore was designed to assess the knowledge of married men on child preparedness as well as to determine their level of involvement in birth preparedness. The data generated from this study is aimed at guiding health workers, health educators and all female reproductive health intervention researchers who mostly focus their attention on women on matters related to child bearing, on the need to develop strategies to involve men in birth preparedness. It is also aimed at stressing the need for joint efforts of couples in planning in terms of saving money, planning for transportation to the health centre, planning for blood donor towards the delivery period and in all other elements of birth preparedness.

\section{Methodology \\ Study Design}

This study adopted a descriptive cross-sectional design using a pretested structured intervieweradministered questionnaire.

\section{Study Site}

The study was carried out at Ibadan North Local Government Area (Figure 1) which is located approximately on longitude $8^{\circ} 5^{\prime}$ East of the Greenwich meridian and latitude $7^{\circ} 23^{\prime}$ North of equators. It is the largest populated local government area in Ibadan, Oyo State Nigeria with a land area of $145.58 \mathrm{~km}^{2}$ which is approximately $4.66 \%$ of the total land area of Ibadan City. It has a population of 306,795. Ibadan North Local Government Area comprises of 12 wards. The local government is bounded in the North by Akinyele Local Government, in the West by Ido Local Government, Ibadan South west and Ibadan South East and bounded in the East by Ibadan North East and Lagelu Local government. It consists of multi-ethnic nationalities predominantly dominated by the Yorubas, but also consists of the Igbos, Edos, Urhobos, Itsekiris, Ijaws, Hausas, Fulani and foreigners who are from Europe, Asia and other parts of the world. The inhabitants are mostly traders, lecturers, civil servants, students and politicians. The Local Government also houses several educational institution such as the University of Ibadan, the Polytechnic Ibadan and several private and public secondary and primary schools, as well as health institutions including the University College Hospital, Adeoyo Maternity Teaching Hospital, 15 primary health centers and several private hospitals. 


\section{Study sample, population and sampling}

Sample size for this study was estimated from Taro Yamane's (1967) formula for single proportion. A total of 302 sample size was calculated and were the ones who participated in the study. The study population included married men aged 20 years and above who had at least one child within two years of the time of data collection. A multi-stage sampling procedure was used to select the 302 married men for this study.

Stage 1: Ibadan North Local Government was stratified into inner core, transitory and peripheral areas.

Stage 2: Two communities were chosen from each stratum making a total of 6 community selected. This was done using simple random sampling. See table 1

Stage 3: Married men who met the inclusion criteria and consented to participate in the study were chosen from the houses in the selected communities using balloting without replacement and 101 married men were chosen from each of the 3 strata.

\section{Instrument for data collection}

A structured interviewer administered questionnaire was used for data collection. The questionnaire was divided into four sections: section one was designed to elicit data on sociodemographic characteristics of the respondents, section two contained questions on knowledge of birth preparedness and danger signs in pregnancy, section three was designed to collect information on male involvement in the practice of birth preparedness while section four contained questions on factors influencing male involvement in birth preparedness.

\section{Data collection procedure}

For the study, serially numbered copies of interviewer-administered questionnaire were used. The data were collected by the researcher with the help of three (3) research assistants who were trained prior to the time of data collection. The questionnaires were printed in English and Yoruba Language such that participants who could not communicate in English can be interviewed with the Yoruba version. Both the benefits and the possible harms that may arise as a result of participating in the study were explained to the research participants. The informed consent forms were distributed to the potential participants after they had been given adequate information about the study. Then, after the copies of the questionnaire were filled, the researcher checked for completeness and errors before leaving the field.

\section{Data management and analysis}

Serial numbers were written on each copy of the questionnaire for easy entry and recall. A coding guide was developed along with the data collection tool in order to facilitate its analysis. Completed copies of the questionnaire were also reviewed to ensure consistency and completeness. Cleaning, recording and coding of data for analysis were also done. Using the coding guide, the data collected were entered into the statistical software and analysed using descriptive statistics such as mean, median and mode and inferential statistics such as Chi-square. The results obtained from the Statistical Package for Social Science (SPSS version 20) analysis were summarized and presented in tables and charts.

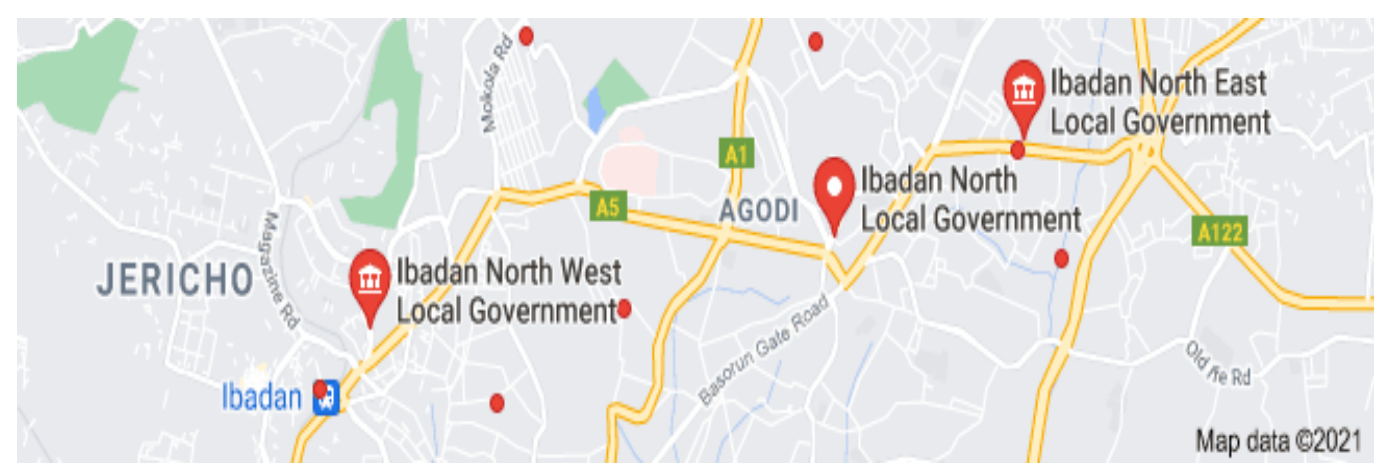

Figure 1: Map of the Study Area 
Table 1: Community Selection

\begin{tabular}{ccccc}
\hline S/N & & Strata & Total \\
\cline { 1 - 3 } & Selected Transitory & Selected Peripheral & Selected Inner core & \\
\hline 1 & communities & communities & & 3 \\
2 & Sango & Bodija & Yemetu & 3 \\
\hline
\end{tabular}

Respondent's knowledge of birth preparedness was measured on a 24 items and 48 point knowledge scale. Knowledge score (KS) of $\geq 34$ was rated good, KS of $\geq 20<34$ was considered fair knowledge and $\mathrm{KS}<20$ was rated as poor knowledge

A 15 -item and 30 point male involvement practice scale was used to examine male involvement on birth preparedness. A practice score of $\geq 23$ represent high involvement while a score of $<23$ represent low involvement towards birth preparedness. Factors influencing male involvement were presented in percentages.

\section{Ethical consideration}

Ethical approval was obtained from the Oyo State Ministry of Health Research Ethics Committee before going to the field for data collection to ensure the study meets all the principles and National guidelines in research involving human participants

Results

Socio-Demographic Characteristics of the Respondents

A total of 302 married men (fathers of Under-5 children) participated in this study (see table 2). The mean age of the respondents was $38.01 \pm 8.6$

\section{Table 2: Socio-Demographic Characteristics of Respondents}

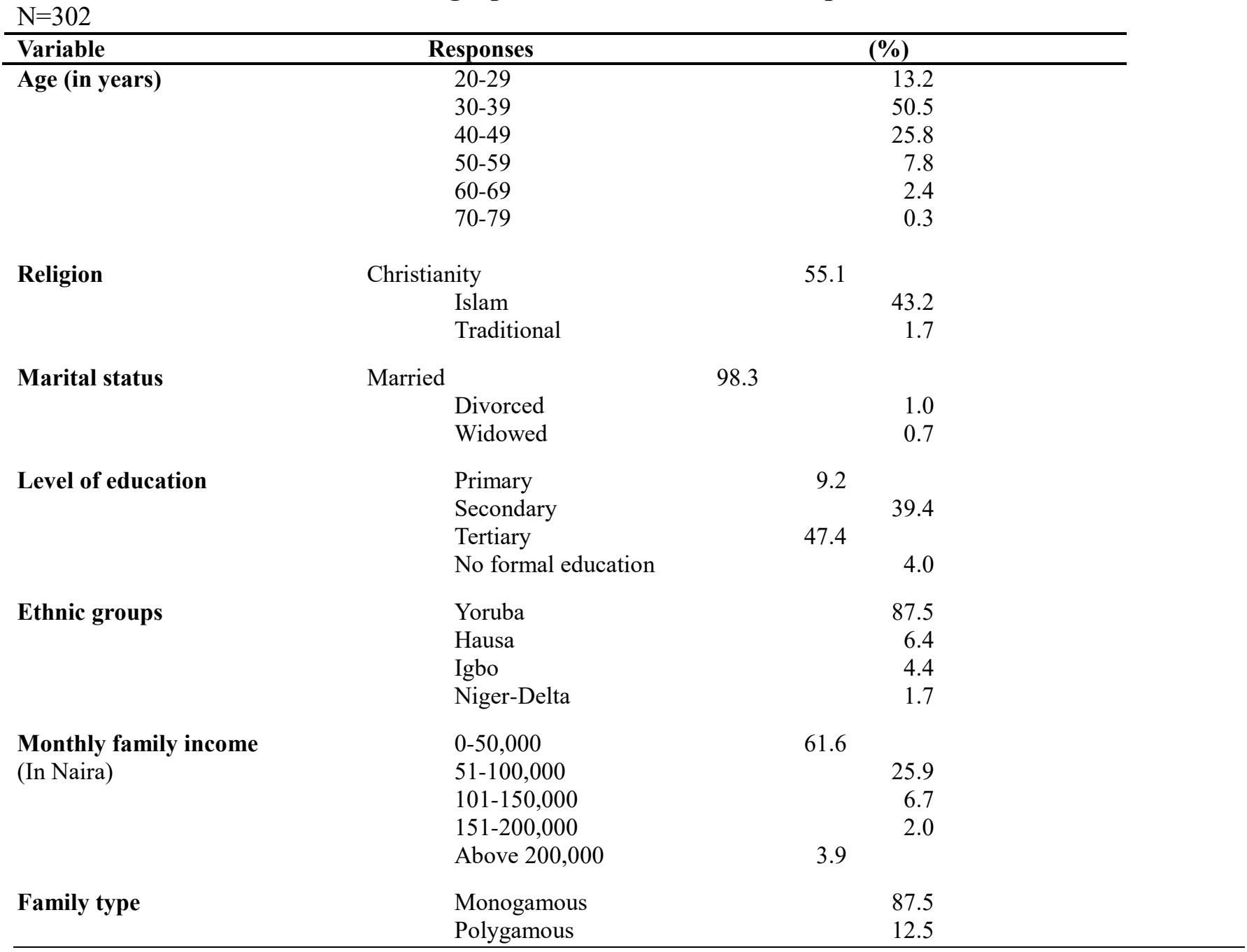


years with a minimum and maximum age of 20.0 and 72.0 years respectively. Except for few, 4.0\% who had no formal education, $9.3 \%$ of the respondents have primary education, $39.4 \%$ had secondary education and $47.4 \%$ had tertiary education. The predominant ethnic group among the respondents was Yoruba (87.5\%). Almost all (92.3\%) the respondents were living with their spouses and $50.7 \%$ of the respondents jointly with spouse make decision regarding family health care while only $36.1 \%$ make the decisions by themselves.

\section{Respondents' awareness and sources of information on birth preparedness}

Majority, (91.3\%) of the respondents were aware of birth preparedness while $8.6 \%$ have never heard about child preparedness before. The Respondents' sources of information included spouse $(56.3 \%)$, Health workers $(46.2 \%)$, friends $(44.1 \%)$ and Mass media (35.5\%). It was a multiple response.

\section{Respondents' knowledge of birth preparedness}

Respondents' total knowledge score is presented in presented in table 3. The mean knowledge score was 33.54 \pm 6 . Majority, $181(59.9 \%)$ of the respondents had good knowledge score, 116(38.4\%) had fair knowledge score while $5(1.7 \%)$ had poor knowledge score of birth preparedness (See table 3 )

\section{Respondents' knowledge of danger signs in pregnancy and signs of labour in pregnancy}

Blurred vision was reported by $65.9 \%, 52.5 \%$ reported swelling of hands, feet and face, $63.4 \%$ reported fit or convulsion, $84.7 \%$ reported reduction or absence of foetal movement and $59.9 \%$ reported fever as a danger sign in pregnancy.

Blood stained mucus from the vagina, was reported by $85.9 \%$ as sign of labour while foetal movement was reported by $68.7 \%$. Also, $72.5 \%$ reported drainage of water from the woman's vagina and $47.6 \%$ reported nausea. (See table 4 )

\section{Respondents' involvement in practice of birth preparedness}

Respondents' involvement in practice of birth preparedness is presented in the table 5. Majority, $172(57.0 \%)$ of the respondents scored low on a 30-point male involvement practice scale while $130(43.0 \%)$ had high score on male involvement practice scale towards birth preparedness. Practice Score (PS) $\leq 23$ was rated as low involvement while PS $>23$ was rated high involvement. The mean practice score was $21.52 \pm 5.4$ while the lowest and higher practice score were 0.0 and 30.0 respectively.

\section{Factors militating against male involvement in birth preparedness}

Factors influencing male involvement in birth preparedness are presented in table 6. Low economic status was the most reported factor by $82.9 \%$ of the respondents, about $45.2 \%$ of the respondents reported busy scheduled at work as a factor and $21.2 \%$ reported attitude of health workers. Cultural belief and inadequate knowledge about birth preparedness were reported by $22.3 \%$ and $46.0 \%$ respectively.

\section{Percentage Distribution of male involvement in child preparedness by Selected Respondents Characteristics}

The relationship between level of involvement with respondents' characteristics shows that there is a significant relationship between knowledge and religious orientation about birth preparedness and involvement. However, the family type of men was shown not to have a relationship with the involvement of men in child preparedness (see table 7) 
$\mathrm{N}=302$

\section{Table 3: Respondents' knowledge of birth preparedness}

\begin{tabular}{|c|c|c|}
\hline Knowledge statements & Yes $(\%)$ & No $(\%)$ \\
\hline Birth preparedness involves identifying skilled birth attendant & $64.9 *$ & 35.1 \\
\hline Birth preparedness involves identifying facility for delivery & $96.6 *$ & 3.4 \\
\hline $\begin{array}{l}\text { Early registration for ante-natal is an element of birth } \\
\text { preparedness }\end{array}$ & $96.0 *$ & 4.0 \\
\hline $\begin{array}{l}\text { Informing friends about expected date of delivery is an } \\
\text { important aspect of birth preparedness }\end{array}$ & 14.9 & $85.1 *$ \\
\hline $\begin{array}{l}\text { Planning for mode of transportation to the hospital for } \\
\text { delivery is important in birth preparedness }\end{array}$ & $68.0^{*}$ & 32.0 \\
\hline $\begin{array}{l}\text { It is necessary to purchase essential materials while preparing } \\
\text { towards delivery }\end{array}$ & $97.7 *$ & 2.3 \\
\hline $\begin{array}{l}\text { Saving money towards delivery is an element of birth } \\
\text { preparedness }\end{array}$ & $90.6^{*}$ & 9.4 \\
\hline $\begin{array}{l}\text { Identifying potential blood donor is an element of birth } \\
\text { preparedness }\end{array}$ & $43.1 *$ & 56.9 \\
\hline $\begin{array}{l}\text { Identifying person who will care for the kids at home while } \\
\text { away for delivery is necessary }\end{array}$ & $74.9 *$ & 25.1 \\
\hline $\begin{array}{l}\text { Strictly adhering to the decision of mothers-in-law on what to } \\
\text { do is important in birth preparedness }\end{array}$ & 49.0 & $51.0 *$ \\
\hline $\begin{array}{l}\text { A pregnant woman and her spouse should be able to identify } \\
\text { labour signs and danger signs }\end{array}$ & $92.2 *$ & 7.8 \\
\hline It is important to have knowledge of expected date of delivery & $94.9 *$ & 5.1 \\
\hline $\begin{array}{l}\text { Pregnancy and delivery matters should be handled by women } \\
\text { alone }\end{array}$ & 6.8 & $93.2 *$ \\
\hline $\begin{array}{l}\text { It is important for pregnant woman to know her blood group, } \\
\text { genotype, blood level and HIV status }\end{array}$ & $97.3^{*}$ & 2.7 \\
\hline $\begin{array}{l}\text { Men do not have to be involved in pregnancy and delivery } \\
\text { care }\end{array}$ & 10.7 & $89.3^{*}$ \\
\hline
\end{tabular}

*Correct responses

Mean knowledge score was 33.54 \pm 6 
Table 4: Respondents' knowledge of danger signs in and signs of labour in pregnancy $\mathrm{N}=302$

\begin{tabular}{|c|c|c|}
\hline Variables & Responses & $\%$ \\
\hline \multicolumn{3}{|l|}{ Danger signs } \\
\hline \multirow{2}{*}{ Blurred Vision } & Yes* & 65.9 \\
\hline & No & 34.1 \\
\hline \multirow[t]{2}{*}{ Swelling of hands, feet and face } & Yes* & 52.5 \\
\hline & No & 47.5 \\
\hline \multirow[t]{2}{*}{ Fits or convulsion } & Yes* & 63.4 \\
\hline & No & 36.6 \\
\hline \multirow[t]{2}{*}{ Reduction or absent of foetal movement } & Yes* & 84.7 \\
\hline & No & 13.3 \\
\hline \multirow[t]{2}{*}{ Fever } & Yes* & 59.9 \\
\hline & No & 40.1 \\
\hline \multicolumn{3}{|l|}{ Labor sign } \\
\hline \multirow[t]{2}{*}{ Blood stained mucus(show) from the vagina } & Yes* & 85.9 \\
\hline & No & 14.1 \\
\hline \multirow[t]{2}{*}{ Foetal (Baby) movement } & Yes* & 68.9 \\
\hline & No & 31.1 \\
\hline \multirow[t]{2}{*}{ Drainage water } & Yes* & 72.5 \\
\hline & No & 27.5 \\
\hline \multirow[t]{2}{*}{ Nausea } & Yes* & 47.6 \\
\hline & No & 52.4 \\
\hline
\end{tabular}

\footnotetext{
${ }^{*}$ Correct responses
} 
Table 5: Respondents' involvement in practice of birth preparedness

\begin{tabular}{lll} 
& & $\mathrm{N}=302$ \\
\hline Male involvement statement & Responses & $\%$ \\
\hline I always know my wife's expected date of delivery & Yes & 87.3 \\
& No & 12.7 \\
I ensure that my wife book early at the health facility & Yes & 95.3 \\
& No & 4.7 \\
I make personal savings toward my wife delivery & Yes & 87.6 \\
& No & 12.4 \\
My wife and I makes decision on where to book for ANC & Yes & 80.1 \\
& No & 19.9 \\
I have accompanied my wife for ANC in the past & Yes & 49.0 \\
& No & 51.0 \\
I always accompany my wife to the health facility for delivery & Yes & 83.1 \\
& No & 16.9 \\
I delegate people that accompany my wife to the hospital for & Yes & 51.9 \\
delivery & No & 48.1 \\
I ensure financial support during my wife's pregnancy & Yes & 94.9 \\
& No & 5.1 \\
I decide with my wife on what to buy towards delivery & Yes & 74.2 \\
I decide with my wife where to buy delivery materials & No & 25.8 \\
& Yes & 24.8 \\
I always observe my wife closely for any danger sign & No & 75.2 \\
pregnancy & Yes & 89.2 \\
I always plan ahead towards transporting my wife to the hospital & Yes & 10.8 \\
at delivery & No & 59.4 \\
I ensure that my wife takes her prescribed drugs & Yes & 40.6 \\
& No & 95.6 \\
My wife and I do not have to plan ahead for potential blood & Yes & 38.2 \\
donor & No & 61.8 \\
I support my wife during pregnancy and after delivery with & Yes & 82.2 \\
some household chores & No & 17.8 \\
\hline
\end{tabular}


$\mathrm{N}=302$

Table 6: Factors influencing male involvement in birth preparedness

*Factors affecting male involvement

Low economic status

Num \%

ber

$248 \quad 82.9$

Inadequate knowledge about birth preparedness

$137 \quad 46.0$

Busy schedule at work

$135 \quad 45.2$

Cultural belief

Attitude of health workers

$63 \quad 21.2$

Religious belief

17.6

Distance of health care facilities

$50 \quad 16.8$

Influence of friends

44

14.7

Influence of family

$44 \quad 14.7$

Quarrel between couples

16

5.3

*Multiple responses

Table 7: Distribution of male involvement in child preparedness by Socio-demographics

\begin{tabular}{llllll}
\hline $\begin{array}{l}\text { Respondents } \\
\text { Characteristics }\end{array}$ & \multicolumn{2}{l}{ Level of involvement } & Total & Df & $\begin{array}{c}\boldsymbol{X} \text {-value } \\
\text { P-value }\end{array}$ \\
\hline Knowledge & Low (\%) & High (\%) & & \\
Poor & $5(100.0)$ & $0(0.0)$ & $5(100.0)$ & 2 & 11.648 \\
Fair & $77(66.4)$ & $39(33.6)$ & $116(100.0)$ & & $0.001^{*}$ \\
Good & $90(49.7)$ & $91(50.3)$ & $181(100.0)$ & & \\
Total & $172(57.0)$ & $130(43.0)$ & $302(100.0)$ & & \\
& & & & \\
Religion & & & $166(100.0)$ & 2 & \\
Christianity & $85(51.2)$ & $81(48.8)$ & $130(100.0)$ & & \\
Islam & $81(62.3)$ & $49(37.7)$ & $5(100.0)$ & \\
Traditional & $5(100.0)$ & $0(0.0)$ & $302(100.0)$ & \\
Total & $172(57.0)$ & $130(43.0)$ & & \\
& & & & \\
Family type & & & & \\
Monogamous & $144(55.6)$ & $115(44.4)$ & $209(100.0)$ & 1 & \\
Polygamous & $23(62.2)$ & $14(37.8)$ & $43(100.0)$ & & \\
Total & $172(57.0)$ & $130(43.0)$ & $302(100.0)$ & \\
\hline
\end{tabular}




\section{Discussion}

Birth preparedness, a very important labour practice was the focus of this study. Almost all the respondents were aware of birth preparedness through several means most of which was through the health workers. A similar study conducted in Nepal by Bhusal et al, (2015) also revealed that more than half of the respondents were aware of birth preparedness, but in contrast to this, was the findings from South Ethiopia in 2015 by Tamiso et al, (2015) which showed that only few (9.4\%) of the married men were aware of birth preparedness. The high awareness in this study may be due to the fact that the study area was an urban centre where there were more educated men, and where there were better opportunities to information through mass media, social media and civilization.

More than half of the respondents had good knowledge score on birth preparedness. Similar to this was a study conducted in western Kenya in 2013 (Kwarbai et al, 2013) which had earlier revealed that most respondent reported that hospital is the best place for delivery and most participants had good knowledge. The result of this finding also corroborated the report by Rahman (2012), in which men agree on joint decision making with their wives as an element of birth preparedness. Also in this line, another related study by Wai et al (2015) documented that majority of men agreed that joint decision making among couples is an element of birth preparedness. This positive response on joint decision-making and male involvement may posit that couple communication and shared negotiation strategies can improve health practices and pregnancy outcomes. Only small percentage of the men did not correctly respond that early registration for ante-natal was an element of birth preparedness. Majority of the respondents reported that planning for mode of transportation to the hospital for delivery is important in birth preparedness, and this is in line with a study conducted in Makelle, Ethiopia (Weldearegey et al, 2015) which also documented that $65.4 \%$ of men identify planning for mode of transportation to the hospital for delivery as an important element of birth preparedness but in contrast to this was another study conducted earlier in Bangladesh (Rahman, et al, 2012) which documented that only $13.1 \%$ of men were concern about mode of transportation.

Most of the men that participated in this study reported that identification of potential blood donor is not essential in birth preparedness, which is similar to the findings from some of the studies previously conducted on birth preparedness (Weldearegey et al, 2015, Ibrahim et al, 2014)

Moreover, during hypothesis testing, this study revealed positive association between knowledge of birth preparedness and male involvement in birth preparedness. Several previous studies have also found correlation between knowledge of birth preparedness and its practice among men. Examples of such are studies conducted in Uganda (Mbalinda et al, 2014), Tanzania (Augusta et al, 2015), and in Ethiopia (Weldearegey et al, 2015)

However, the descriptive level of male involvement in birth preparedness in this study was low. Most studies conducted earlier reported also documented low practice/ involvement among men. For example Weldearegay et al (2015) documented $32.7 \%$ good practice in Ethiopia, $44.3 \%$ good practice was reported in Nepal (Bhusal et al, 2015) and only 6.6\% Nigerian male were earlier reported to be involved in birth preparedness (Ibrahim et al, 2014). Meanwhile, birth preparedness has been found to be very effective in reducing the delays that contribute to death of pregnant and post-partum women and their newborns (USAID, 2001). There have been emphases that birth preparedness is more effective when it is done as a joint effort by the couple. Furthermore, male involvement in birth preparedness and other reproductive health concepts has been found by several studies to be associated with improved maternal health outcomes especially in developing countries (Yargawa \& Leonardi, 2015; Mullany et al, 2005; Guadagno, 2013). These evidences may imply that the low involvement of men in birth preparedness and other maternal health issues as found in this study and other previous studies may be one of the factors responsible for high level of poor pregnancy outcomes in developing countries. 
The most reported factor against male involvement in birth preparedness by the respondents was low socio economic factor. Similar previous studies also noted relationship between socioeconomic status and male involvement in maternal and child health issues. For example a community based study conducted in Ethiopia Weldearegay et al (2015) reported that employed husbands and men who earn more are more involved in birth preparedness. Another similar study carried out in Kenya (Mangeni et al, 2012) also reported that women with high socioeconomic status utilize skill birth attendant more than women with low status. In contrast to all these was a study conducted in Northern Nigeria (Ibrahim et al, 2014) which reported that husbands who earn same or less than their wives were likely to be more involved in birth preparedness. This present study however, showed positive association between level of income of men and birth preparedness. This implies that men who earn more are more likely to be involved in birth preparedness than men who earn less.

\section{Conclusion}

This study has profiled determining factors for male involvement in child preparedness in Southern Nigeria. Majority of the men had good knowledge on birth preparedness whereas the actual practice score was found to be low with evidenced low involvement. Several factors were identified to contribute to lack of male involvement in birth preparedness with socioeconomic factor taking the lead while knowledge is said to be contributing to level of involvement. Effort should be made to further create awareness and educate men, and other family members including mother-in-laws as well as health workers on the importance of involving husbands in the care of their wives and the actual roles that husbands should play to ensure adequate and full involvement.

\section{Acknowledgement}

We acknowledge the participants in this study for their voluntary informed consent

\section{Conflicts of Interest}

There is no conflict of interest

\section{References}

August, F., Pembe, A. B., Mpembeni, R., Axemo, P., \& Darj, E. (2015). Men's knowledge of obstetric danger signs, birth preparedness and complication readiness in Rural Tanzania. PLoS ONE 10(5), 1-12.

Bhusal, C. K., \& Bhattarai, S. (2015). Involvement of male in birth preparedness in tulsipur municipality of dang district Nepal. Journal of Chitwan Medical College 5(14), 33-38.

Dada, S. O., Oyewole O. E., \& Desmennu, A. T. (2020). Knowledge as Determinant of Healthy Eating Among Male Postgraduate Public Health Students in a Nigerian Tertiary Institution. International Quarterly of Community Health Education 0(0) 1-12. https://doi.org/10.1177\%2F0272684X20972895.

Guadagno, M., Mackert, M., \& Rochlen, A. (2013). Improving Prenatal Health: Setting the Agenda for Increased Male Involvement. American Journal of Men's Health 7(6), 523526.

Ibrahim, M. S., Idris, S. H., Abubakar, A. A., Gobir, A. A., Bashir, S. S., \& Sabitu, K. (2014). Determinants of male involvement in birth preparedness among married men in two communities of rural Northern Nigeria. Journal of Community Medicine and Primary Health Care 26 (1), 44-58.

JHPIEGO (2001) Maternal and Neonatal Health Programme Birth Preparedness and Complication Readiness: A Matrix of Shared Responsibilities; English Introductory Text Revised in 2004). Baltimore, MD; 2004 Kwambai, T. K., Dellicour, S., Desai, M., Ameh, C. A., Person, B., Achieng, F., Mason, L., Laserson, K. F., \& Kuile, F., O. (2013). Perspectives of men on antenatal and delivery care service utilization in rural western Kenya: a qualitative study. BMC Pregnancy and Childbirth 13(134), 1-10.

Mangeni, J. N., Mwangi, A., Mbugua, S., \& Mukthar, V. K. (2012). Male involvement in maternal healthcare as a determinant of 
utilization of skilled birth attendants in Kenya. East African Medical Journal 89(11), 372-383.

Mbalinda, S. N., Nakimuli, A., Kakaire, O., Osinde, M. O., Kakande, N., \& Kaye, D. K. (2014). Does knowledge of danger signs of pregnancy predict birth preparedness? A critique of the evidence from women admitted with pregnancy complications. Health Research Policy and Systems 12(60), 1-7.

MEDiCAM. (2004) Male involvement is key to reproductive health. Available from http://www.policyproject.com/pubs/brochures/ CAM_MaleInvolveEng.pdf.

Mullany, B. C., Hindin, M. J., \& Becker, S. (2005) Women's autonomy and male involvement in antenatal care: associations and tensions. Department of population \& family health sciences, Johns Hopkins Bloomberg School of Public Health Baltimore, MD, U.S.A.;

Rahman, M., \& Nicholls, P. (2012). Men's knowledge and awareness of maternal, neonatal and child health care in rural Bangladesh: a comparative cross sectional study. Reproductive Health 9(18), 1-9.

Tamiso, A., Merdekios, A., \& Tilahun, M. (2015). Association of men's awareness of danger sign of obstetric complication and male involvement's in birth preparedness practices at South Ethiopia. International Journal of Public Health Science (IJPHS) 4(1), 63-70.

Udofia, E. A., Obed, S. A., Calys-Tagoe, B. N., \& Nimo, K. P. (2013). Birth and emergency planning: A cross sectional survey of postnatal women at Korle Bu Teaching Hospital, Accra, Ghana. African Journal of Reproductive Health 17(1), 27-40.

USAID (2001) Maternal and neonatal health program. Birth Preparedness and Complication Readiness: A Matrix of Shared Responsibilities. Center for Population, Health and Nutrition, Bureau for Global Programs, Field Support and Research, U.S. Agency for International Development

Wai, K. M., Shibanuma, A., Oo, N. N., Fillman, T. J., Saw, Y. M., \& Jimba, M. (2015). Are husbands involving in their spouses' utilization of maternal care services? A Cross-
Sectional Study in Yangon, Myanmar. PLOS ONE 10(12), 1-13.

Weldearegay H. G. (2015). Determinant factors of male involvement in birth preparedness and complication readiness at Mekelle town; a community based study. Science Journal of Public Health 3(2), 175-180.

WHO (2015). World Health Organization. Recommendations on health promotion interventions for maternal and newborn health. Geneva;

WHO, (2019). World Health Organization. Fact sheet on maternal mortality. Available from http://www.who.int/mediacentre/factsheets/fs3 48/en/

Yamane. T. (1967). Statistics: An Introductory Analysis, 2nd Ed., New York: Harper and Row.

Yargawa, J., \& Leonardi-Bee, J. (2015). Male involvement and maternal health outcomes: systematic review and meta-analysis. $J$ Epidemiol Community Health, 69(6), 604-612. 